\title{
MyPyramid Ways to Fruits and Vegetables for Your Child
}

\author{
Glenda L. Warren
}

Set a good example for children. Eat and serve fruit and vegetables everyday with meals and as snacks!

\section{Allow them to be involved while shopping for fruits and vegetables:}

- For those times when you take the children with you to shop for food, teach them to help with the shopping.

- While shopping, let your child pick out a new fruit and a new vegetable to try later at home.

- Teach them to find the nutrition facts panel on the food label.

- Show them how to look for the canned fruits with no added sugar.

- $\quad$ Teach them how to choose fruits and vegetables that are firm. Avoid those that are bruised, shriveled, wilted, or have mold or other signs of spoilage.

- Teach them how to place foods in the shopping cart. Be sure heavy items or raw meats are not on top of fruits and vegetables.
- Let them know that you are reading the store ads in search of the best bargains.

- Let them help select packages of frozen fruits and vegetables that do not have any signs of thawing.

\section{Allow them to be involved in preparing fruits and veggies:}

- Use age appropriate activities and allow children to help clean, peel, shell, or cut up vegetables and fruits. They can also help shell peas and snap beans.

- Younger children should not be involved in cutting up and chopping foods. They should not be involved in shelling peas and beans so they won't be tempted to put these in their ears or nostrils.

- Make fruit kabobs using pineapple chunks, bananas, grapes, berries or other fruits. Only give these to older children or use small pieces so there won't be any choking hazards!!!

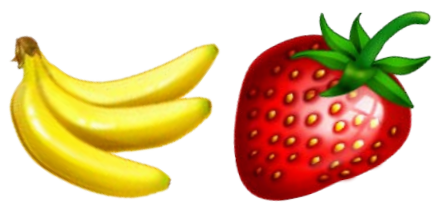

1. This publication is FCS8866, one of a series of the Department of Family, Youth and Community Sciences, Florida Cooperative Extension Service, Institute of Food and Agricultural Sciences, University of Florida. First published: December 2008. Please visit the EDIS Web site at http://edis.ifas.ufl.edu

2. Glenda L. Warren, M.S., R.D., CFCS, associate professor, Extension Nutritionist - EFNEP, Department of Family, Youth and Community Sciences, Florida Cooperative Extension Service, Institute of Food and Agricultural Sciences, University of Florida, Gainesville, Florida 32611 - 0310. Publication date: 
- Teach them to make fruit kabobs for snacks or for birthday party treats.

- Always emphasize the importance of food safety.

- Teach them how to wash hands for food safety.

- Teach them how to wash fruits and vegetables for food safety.

\section{Give them a chance to make decisions:}

- Let children help plan what vegetables and fruits will be served for meals and snacks or salads.

\section{Serve the foods in ways that are appealing to children:}

- $\quad$ Use cut-up vegetables and/or fruits for snacks.

- Children often prefer foods served separately. For example, rather than mixed vegetables, try serving two vegetables separately.

- Decorate plates or serving dishes with fruit slices.

- Top off a bowl of cereal with some berries. Or, make a smiley face with sliced bananas for eyes, raisins, for a nose, and an orange slice for a mouth.

\section{Do everything you can to help them get the best nutrition:}

- Offer raisins or other dried fruits instead of candy.

- Buy only $100 \%$ juice for children's meals or snacks versus soda or other sugar-sweetened beverages. Be a label reader so you will know if you are buying $100 \%$

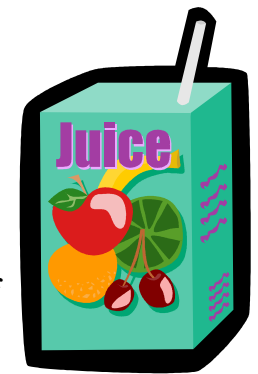

juice or just juice drink.

- When eating at a fast food restaurant, take advantage of available fruit choices, such as sliced apples, mixed fruit cup, or 100\% fruit juice.

- Offer the real fruit pieces and $100 \%$ fruit juice to the children. There is often little fruit in "fruit flavored" beverages or chewy fruit snacks.

- Limit fruit juices to $1 / 2$ to $3 / 4$ cup (4-6 oz) per day.

Make it a daily habit to provide a variety of choices from the fruit group and from the vegetable group. And always set a good example-let your children see that you eat fruits and vegetables too! 